\title{
Female genital mutilation: prevalence, perceptions and effect on women's health in Kersa district of Ethiopia
}

This article was published in the following Dove Press journal:

International Journal of Women's Health

9 February 2012

Number of times this article has been viewed

\author{
Wondimu Shanko Yirga ${ }^{1,2}$ \\ Nega Assefa Kassa ${ }^{2}$ \\ Mengistu Welday \\ Gebremichael $^{2}$ \\ Arja R Aro ${ }^{3}$
}

'University of Southern Denmark, Faculty of Health Sciences, Esbjerg, Denmark; ${ }^{2}$ Haramaya University College of Health Sciences, Harar, Ethiopia; ${ }^{3}$ University of Southern Denmark, Unit for Health Promotion Research, Esbjerg, Denmark
Correspondence: Wondimu Shanko Yirga University of Southern Denmark, Faculty of Health Sciences, Niels Bohrs Vej 9, 6700 Esbjerg, Denmark Tel +45 50677022

Fax +45 65504283 (Attn: Arja R Aro)

Email wondimus@yahoo.com
Background: Female genital mutilation (FGM) is nontherapeutic surgical modification of the female genitalia. It is an ancient tradition in large parts of Africa, including Ethiopia, especially in the eastern part of the country. This study aimed to identify the prevalence, perceptions, perpetuators, reasons for conducting FGM, and factors associated with this practice with regard to women's health.

Methods: Community-based cross-sectional house-to-house interviews were conducted during 2008 among 858 females of reproductive age (15-49 years), in Kersa district, East Hararge, Oromia region, Ethiopia. Proportions and Chi-square tests were used to describe the data and logistic regression was used to describe statistical associations. Statistical significance was set at $P<0.05$.

Results: FGM was reported to be known by 327 (38.5\%) of the interviewees. The majority ( $n=249,76.1 \%$ ) reported that local healers were the main performers of FGM, and 258 (78.9\%) respondents stated that the clitoris was the part removed during circumcision. The main reason for the practice of FGM was reduction of female sexual hyperactivity (reported by 198 women [60.3\%]). Circumcision of daughters was reported by $288(88.1 \%)$ respondents, and this showed a statistically significant association with the Christian religion $(P=0.003)$, illiteracy $(P=0.01)$, and Amhara ethnicity $(P=0.012)$. The majority of the respondents $(792$, $92.3 \%$ ) were themselves circumcised and $68.8 \%$ did not know of any health-related problems associated with FGM.

Conclusion: In spite of FGM being a common practice in the study area, only one third of the respondents stated that they knew about it. Local healers were the main performers of FGM. Some of the women knew about the negative reproductive health effects of FGM and some had also experienced these themselves. However, only a few had tried to stop the practice and the majority had taken no steps to do so. This may be attributable to the fear of becoming alienated from the cultural system and fear of isolation.

Keywords: female genital mutilation, reasons, health consequences, Ethiopia

\section{Introduction}

Female genital mutilation/cutting is any surgical modification of the female genitalia, comprising all procedures involving partial or total removal of the external female genitalia or other injury to the female genital organs for cultural or nontherapeutic reasons. It is an ancient traditional practice in large parts of Africa. A World Health Organization interagency group has classified female genital cutting into four types: type 1, partial or total removal of the clitoris and/or the prepuce (clitoridectomy); type 2, partial or total removal of the clitoris and labia minora, with or without excision of the labia majora (excision); type 3, narrowing of the vaginal orifice with creation of a covering seal by 
cutting and appositioning the labia minora and/or the labia majora, with or without excision of the clitoris (infibulation); and type 4, all other harmful procedures to the female genitalia for nonmedical purposes, eg, pricking, piercing, incising, scraping, and cauterization. Herein, the term "female genital mutilation" (FGM) is used, because this term is recommended by the World Health Organization and all UN agencies. ${ }^{1}$

It is estimated that about 100-140 million girls and women worldwide have undergone FGM, and each year a further two million girls and women are at risk of this practice. It is performed on girls aged 4-12 years and in some cultures as early as a few days after birth or as late as just before marriage. ${ }^{2}$ Most of the girls and women affected live in 28 African countries, but also in the Middle East and Asia. They are also increasingly found in Europe, Australia, New Zealand, Canada, and US, mostly among immigrants from cultures where FGM is a tradition. ${ }^{3}$ The prevalence of FGM according to figures from African countries shows a prevalence of more than $70 \%$ in Burkina Faso, Djibouti, Egypt, Eritrea, Ethiopia, Guinea, Mali, Mauritania, Northern Sudan, and Somalia. However, there is great variation in prevalence between and within countries, reflecting ethnicity and tradition. ${ }^{4}$ For example, the prevalence rate is $92 \%$ in Mali as compared with $28 \%$ in Senegal.

It is estimated that $15 \%$ of all circumcised women have undergone the most severe form of FGM, ie, infibulation, which involves the stitching and narrowing of the vaginal opening. However, approximately $80 \%-90 \%$ of all circumcisions in Djibouti, Somalia, and Sudan are of this type. ${ }^{1,2}$ Prevalence data are available from the demographic and health survey reports of each country. Recent surveys have found that $90 \%$ of girls in Egypt who had undergone FGM were 5-14 years of age when subjected to the procedure; $50 \%$ of those in Ethiopia, Mali, and Mauritania were under 5 years of age; and $76 \%$ of those in Yemen were not more than two weeks of age. In some communities, women who are about to be married, are pregnant with their first child, or have just given birth also undergo the practice, and in Ethiopia the prevalence of FGM among women of child-bearing age who have undergone FGM is $80 \%$, whereas the rate for women who have undergone FGM themselves where at least one daughters has also undergone FGM is $48 \% .^{5}$ A study conducted among schoolgirls in Egypt has shown that the overall prevalence of FGM among girls aged 10-18 years was $50.3 \%$. In rural schools, the prevalence was $62 \%$ as compared with $42 \%$ in urban schools. ${ }^{6}$

FGM is mainly practiced by traditional/local healers in various parts of the world who may not have professional experience in surgical procedures. In some countries, medical personnel, including doctors, nurses, and certified midwives, perform FGM. Highest rates of medical personnel performing the procedure are found in Egypt (61\%), Kenya (34\%), and Sudan (36\%). In Guinea and Nigeria, 9\% and 13\%, respectively, of FGMs are carried out by medical personnel, whereas more than $90 \%$ of FGM procedures in Guinea and Eritrea are performed by traditional/local healers. ${ }^{3}$

There are many reasons for the practice of FGM, and it is often described as a means to safeguard against premarital sexual activity and, as such, prevent female promiscuity and preserve virginity. In Kenya, 30\% of women supporting continuation of the practice agreed that FGM helped to preserve virginity and avoid immorality. In Nigeria, similar rates $(36 \%)$ were reported by women, while $45 \%$ of men supporting continuation of the practice agreed with this statement. FGM was believed to be proof of a girl's virginity, thereby improving the marriage prospects of unmarried girls who have undergone the procedure. In Côte d'Ivoire, "improved marriage prospects" was cited by $36 \%$ of women favoring continuation of the practice once married. FGM is also believed by some communities to ensure that a woman is faithful and loyal to her husband. For example, 51\% of women in Egypt believe that FGM prevents adultery.

In another similar World Health Organization study in Egypt, 33.4\% of subjects perceived the practice of FGM to be a religious tradition, and the most important reason for performing FGM in Egypt. All in all, 72\% of ever married women reported that FGM is an important part of religious tradition. ${ }^{6}$ The distribution of female genital cutting in Ethiopia varies depending on ethnic origin and region. In 1997-1998, the National Committee on Traditional Practices in Ethiopia carried out a national baseline survey to determine the prevalence of this practice. Some 44,000 people were interviewed in a study reaching 65 of Ethiopia's 80 ethnic groups (urban and rural) in all ten regions of the country. The published results show that $72.7 \%$ of the female population have undergone a form of circumcision. Regional statistics from the survey revealed that prevalence ranges from $27.1 \%$ in the Gambella region to $99.7 \%$ in the Somali region, and to more than $50 \%$ in the capital, Addis Ababa. ${ }^{78}$ Throughout the country, half of all women who have undergone FGM have had clitoridectomy, and the remaining cases have had their clitoris and/or labia minora cut. Nationwide, $6 \%$ of females affected by the procedure have undergone infibulation. More than $80 \%$ of women in the Somali region are suffering as a result of infibulation, whereas the prevalence is $60 \%$ in Afar. ${ }^{9}$ For instance, in a local baseline survey in the Amhara 
region, six woreda (local districts) showed significant between-district differences in the prevalence of FGM. The low-prevalence group showed an FGM rate ranging from $1.4 \%$ to $21.9 \%$, whereas the prevalence varied between $37.9 \%$ and $72.9 \%$ in the high-prevalence group. The practice is more prevalent among Muslims in all regions. ${ }^{10}$

\section{Methods and materials}

A community-based cross-sectional interviewer-administered questionnaire in a house-to-house survey was conducted in the Kersa Demographic Surveillance and Health Research Center field site among 858 women of reproductive age (15-49 years) from January to February 2008. The study was conducted in selected 12 rural and urban kebeles using proportion to size of the existing householders in each kebele. This study site was specifically selected as part of a field research site where the research center for demographic surveillance and health research is located and various projects are being undertaken on different health-related topics in Kersa district. Study subjects were recruited based on their age category from the source population in Kersa.

Sample size was calculated and distributed among 12 kebeles/localities proportional to the size of households in each kebele. Study households were selected from each kebele by systematic random sampling from the random start point. The household interval in each kebele was determined by dividing the total number of households into the sample size. Subsequent households were included in the study and identified systematically through house-to-house visits, each time adding the sampling interval to the previous number. One woman of reproductive age with a husband was interviewed per household. If more than one eligible female was found in the household, a woman having a husband was interviewed.

Because different issues related to health were asked, administered together, and if more than one woman with a husband was found in the house, a lottery method was used to determine which woman would be interviewed. In the event of no eligible woman being found in a selected household, the next and subsequent households were visited. Data collectors who had completed high school education were trained before they administered the questionnaire, and a pretest or sample data collection was conducted ahead of official data collection.

The questionnaire addressed women's knowledge about FGM, whether the women were circumcised themselves or not, and who were the main perpetuators of FGM in the region. A questionnaire was developed first in English and was then translated back into the local language (Amharic), and the translated Amharic version was administered. The data collectors visited house-to-house and interviewed women in the reproductive age group (15-49 years) in each household selected for study. If the member of the household who was eligible to be a study subject was not present at the time of the visit, a second visit was arranged and the data were obtained. If a revisit was not possible, the next randomly selected household was selected.

The data collected were checked on a daily basis for completeness and appropriateness. Before starting data collection, the proposal had passed through the ethical committee of Haramaya University and ethical clearance was obtained. Approval was secured from the local authorities, and verbal consent was obtained from participants during individual house-to-house interviews. For the sake of confidentiality, any label identifying the respondent was avoided in the questionnaire. Thus, the data were made anonymous. The data collected were analyzed using the SPSS statistical package version 16.0 (SPSS Inc, Chicago, IL). Proportions, Chi-square tests, and odds ratios (OR) were used to describe the data and $P<0.05$ was considered to be statistically significant.

\section{Results}

The study was conducted among 858 women in Kersa local districts/selected kebeles. The age group 20-44 years comprised $79.6 \%$ of participants. Muslim, illiterate, and married women comprised $95 \%, 84 \%$, and $89 \%$ of the study participants, respectively (Table 1). The sociodemographic variables were skewed and not representative of the national data. In Ethiopia, certain groups of people are concentrated in certain areas. For example, Muslims are dominant in some communities in eastern and southwestern parts of Ethiopia, whereas Christians are dominant in the northern, southeastern, and central parts of the country. Housewives were overrepresented, which is probably due to the high proportion (85\%) of the population living in rural areas where women stay at home to serve their husbands and take care of children. The majority of women were legally married, given that the study was intended to obtain data from married women, and some women who were cohabiting but not legally married were included as single women.

In total, 327 respondents $(38.5 \%)$ reported the existence of FGM in the community at the time of the interview. These respondents were further asked about who performed FGM, why it was practiced, how the cutting was done, and if their daughters had been cut. Women were also questioned about 
Table I Sociodemographic characteristics of women interviewed in Kersa district, East Hararge, Oromia region Ethiopia, January $2008, n=858$. (Totals vary from 805 to 858 due to missing values)

\begin{tabular}{|c|c|c|}
\hline Variables & Frequency & Percentage \\
\hline \multicolumn{3}{|l|}{ Age } \\
\hline $15-19$ & 39 & 4.8 \\
\hline $20-24$ & 113 & 14.0 \\
\hline $25-29$ & 153 & 19.0 \\
\hline $30-34$ & 154 & 19.1 \\
\hline $35-39$ & $|3|$ & 16.3 \\
\hline $40-44$ & 100 & 12.4 \\
\hline $45-49$ & 35 & 4.3 \\
\hline $50+$ & 80 & 9.9 \\
\hline Total & 805 & 100 \\
\hline \multicolumn{3}{|l|}{ Religion } \\
\hline Muslim & 811 & 95.2 \\
\hline Orthodox & 34 & 4.0 \\
\hline Protestant & 7 & 0.8 \\
\hline Total & 852 & 100.0 \\
\hline \multicolumn{3}{|l|}{ Educational level } \\
\hline Cannot read/write & 723 & 84.3 \\
\hline Can read and write & 52 & 6.1 \\
\hline Primary ( $1-8$ grade) & 49 & 5.7 \\
\hline Secondary $(9-12)$ & 22 & 2.6 \\
\hline Tertiary $(12+)$ & 12 & 1.4 \\
\hline Total & 858 & 100.0 \\
\hline \multicolumn{3}{|l|}{ Marital status } \\
\hline Single & 31 & 3.6 \\
\hline Married & 761 & 89.4 \\
\hline Divorced & 10 & 1.2 \\
\hline Widowed & 49 & 5.8 \\
\hline Total & 851 & 100.0 \\
\hline \multicolumn{3}{|c|}{ Occupational status/employment } \\
\hline House wife & 800 & 95.6 \\
\hline Government/NGO & 7 & 0.8 \\
\hline Student & 2 & 0.2 \\
\hline Street vendor & 15 & 1.8 \\
\hline Farmer & 19 & 2.2 \\
\hline Other & 3 & 0.4 \\
\hline Total & 846 & 100.0 \\
\hline \multicolumn{3}{|l|}{ Ethnicity } \\
\hline Oromo & 821 & 95.7 \\
\hline Amhara & 36 & 4.2 \\
\hline Gurage & 1 & 0.1 \\
\hline Total & 858 & 100.0 \\
\hline
\end{tabular}

Abbreviation: NGO, nongovernment organization.

the part of the organ that the healers removed during the practice, and the majority of respondents $(258,78.9 \%)$ said that the clitoris was the main part removed (Table 2).

The main reason given for genital cutting was to reduce "female hyperactivity" in sexual practice, and was the response of two thirds of the women, while a quarter of the women responded that it was done to prevent early initiation of sexual activity (Table 3 ).

The majority of respondents $(249,76.1 \%)$ reported that local healers were the main practitioners of FGM in the
Table 2 Types of FGM being practiced in Kersa district, East Hrarge, Oromia region Ethiopia, in February 2008 according to women interviewed and who knew about this practice $n=327$. Women could cite several types of cutting (percentage calculated below from the total number of types given)

\begin{tabular}{lll}
\hline Type of genital cutting & $\mathbf{n}$ & Percent \\
\hline Clitoris only & 258 & 78.9 \\
Clitoris, labia & 115 & 35.2 \\
Clitoris, labia, and surrounding part & 77 & 23.5 \\
Clitoris, labia, surrounding part and stitching & 34 & 10.4 \\
Other forms & 4 & 1.2 \\
Total & 488 & \\
\hline
\end{tabular}

community, whereas $18 \%$ of procedures were reported to have been performed by elderly people. Participants were asked if they themselves had been circumcised, and 792 (92.3\%) of participants responded "yes", of whom $42.5 \%$ reported having suffered some form of reproductive health problems during delivery and at first sexual intercourse. They were also asked if they had ever seen any person with a complication after FGM, and $44 \%$ reported having seen a woman with excessive bleeding after the procedure. In a logistic regression analysis of background variables and circumcision, women who were living in rural areas had less likelihood of being circumcised than women living in urban areas (OR 0.116, confidence interval [CI] 0.065-0.207, $P<0.001)$. Further, ownership of a radio indicating higher socioeconomic status seemed to be associated with a lower risk of women being circumcised themselves or their daughters being circumcised (OR 1.187, CI 0.678-2.075, $P=0.549$ and OR 1.716, CI 0.982-3.000, $P=0.58$ ), but the statistical association was not significant.

Women who had seen other women with complications after circumcision were asked about their feelings concerning the problems they saw; over two thirds had been frightened

Table 3 Distribution of perceived reasons to practice female genital mutilation in Kersa District, East Hararge, Oromia region, Ethiopia, February 2008, n = 325 (data for two women missing)

\begin{tabular}{lll}
\hline Variable & Frequency & Percentage \\
\hline $\begin{array}{l}\text { Reasons for FGM practices } \\
\begin{array}{l}\text { To reduce female hyperactivity } \\
\text { in sexual practice }\end{array}\end{array}$ & 196 & 60.3 \\
$\begin{array}{l}\text { To prevent females from early } \\
\text { initiation of sex before marriage }\end{array}$ & 82 & 25.1 \\
$\begin{array}{l}\text { To prevent females from } \\
\text { unprotected sex }\end{array}$ & $\mathrm{I}$ & 0.3 \\
$\begin{array}{l}\text { Don't know } \\
\text { Other }\end{array}$ & 31 & \\
Total & 15 & 9.5 \\
\hline
\end{tabular}

Abbreviation: FGM, female genital mutilation. 
when observing other women who were bleeding; one in five thought this was normal; and $15.9 \%$ became sympathetic after the incident. Women were asked if they reported these actions and gave support when problems and complications related to FGM occurred. More than half of the women who encountered women with complications of FGM did nothing and only $12.8 \%$ of them visited health institutions to assist the victims (Table 4).

Participants were asked about their knowledge of the health-related consequences of FGM. The majority (68.8\%) of the 327 respondents did not know of any problems associated with FGM, and only a few noted problems associated with FGM during delivery and sexual intercourse, or were aware of psychological problems associated with the practice. Women who were themselves circumcised $(n=792)$ were asked if they had ever experienced a problem related to circumcision; $41.3 \%$ reported problems during delivery and $30.6 \%$ reported problems during first sexual intercourse (Table 5).

The participants were asked about the role of women in stopping the practice of FGM. The majority of women ( 658 [76.7\%]) had not tried to prevent FGM in the community but some $(199$ [23.2\%]) had attempted to stop it. One quarter

Table 4 Feelings of 327 women seeing serious infection, healthrelated problems, and attempted solutions following genital mutilation performed on others in Kersa district, East Hararge, Oromia region, Ethiopia, February 2008

\begin{tabular}{lll}
\hline Variables & Frequency & Percentage \\
\hline $\begin{array}{l}\text { Feelings of women after seeing serious } \\
\text { infection following circumcision }\end{array}$ & & \\
I was frightened & 205 & 62.7 \\
I thought it was normal & 58 & 17.8 \\
I was in sympathy & 51 & 15.8 \\
No response & 13 & 3.7 \\
Total & 327 & 100.0 \\
Attempted solutions to reproductive & & \\
health problems so far after FGM & & \\
I went for medical support & 42 & 12.8 \\
Consulted traditional healer & 42 & 12.8 \\
Other/specify & 28 & 8.6 \\
Did nothing & 215 & 65.7 \\
Total & 327 & 100.0 \\
Females who have observed these & & \\
problems after FGM & & \\
Excessive bleeding & & \\
Yes & 144 & 44.0 \\
No & 183 & 56.0 \\
Total & 327 & 100.0 \\
Signs of sepsis & & \\
Yes & 100 & 30.6 \\
No & 227 & 69.4 \\
Total & 327 & 100.0 \\
\hline
\end{tabular}

Abbreviation: FGM, female genital mutilation.
Table 5 Knowledge of women about problems associated with female genital mutilation of other persons and of themselves in Kersa district, East Hararge, Oromia region, Ethiopia, February 2008

Frequency Percentage

Knowledge of problems associated with FGM among 327 women reported

by the respondents; more than one

response was allowed; percentages below

calculated from the total number

of responses given, $n=348$

During sexual intercourse

23

7.0

During menstrual flow

Yes

5

1.5

During delivery

Yes

74

22.6

Psychological problems

Yes

21

6.4

Don't know of any associated

problem

Yes

225

68.8

Total $\mathrm{n}=348$

Ever experienced problems associated with FGM themselves $(n=792)$; more than one response was allowed; the percentages below calculated from the total number of responses given, $\mathrm{n}=958$

Pain during sexual intercourse

Yes

128

16.2

During first sexual intercourse

Yes

242

30.6

Sexual dissatisfaction

Yes

128

16.2

During delivery

Yes

327

$4 \mid .3$

Infection

Yes

116

14.6

Other problems

Yes

17

2.1

Abbreviation: FGM, female genital mutilation.

of the respondents did not give any reason why they did not try to stop FGM, adding that "to stop is to interfere with the norm", believing that FGM practice is acceptable and they did not want to stop it at all (Table 6).

\section{Discussion}

In this study, the prevalence of FGM was as high as 94\% among women of child-bearing age in a rural area of eastern Ethiopia. In a similar study in the Somali region of Ethiopia, an even higher prevalence of $97 \%$ was reported. ${ }^{7}$ A study done in Somali refugees in the eastern part of Ethiopia showed an increasing prevalence with age, from $52 \%$ to $95 \%$ at $7-8$ and 11-12 years of age, respectively. ${ }^{7,11}$ The present finding 
Table 6 Women's behavior and attitudes to stopping FGM and reasons not to stop the practice in Kersa district, East Hararge, Oromia region, Ethiopia, February 2008. All 858 participants were asked general questions about FGM practices

\begin{tabular}{lll}
\hline Variables & Frequency & Percentage \\
\hline Attempted to stop FGM practices & & \\
Yes & 199 & 23.2 \\
No & 658 & 76.7 \\
No answer & $\mathrm{I}$ & 0.1 \\
$\quad$ Total & 858 & 100.0 \\
Reasons given not to stop FGM practices, & & \\
$\mathrm{n}=52 \mathrm{I}$, missing values $\mathrm{n}=337$ & & \\
I agree with the practice & 124 & 23.8 \\
To stop is going against the norm & 154 & 29.6 \\
Have no answer & 217 & 41.7 \\
Other & 26 & 4.9 \\
Total & 521 & 100.0
\end{tabular}

Abbreviation: FGM, female genital mutilation.

is close to that of the 2005 Demographic and Health Survey report, with a prevalence of 69\% (urban) and 76\% (rural), respectively, and was also found to be close to surveys done in other populations. ${ }^{12}$ It appears that the rates vary across regions and localities in Ethiopia, being as low as 37\% in the West Belesa region. These prevalence rates are in line with studies from other African countries, where more than $80 \%$ of girls and women are circumcised. ${ }^{2,5}$ This indicates that the prevalence is high in the eastern part of Ethiopia.

Variations in the prevalence of FGM and the reasons why it is performed between countries and regions might reflect the diverse perceptions, culture, and religious practices of the various communities involved. In this study, the main reason given was to reduce "hyperactivity" in sexual practice, with few practicing FGM because of social norms. From this it can be assumed that women are perceived by the community as being unable to control their sexual desires without undergoing some form of genital mutilation. In a similar study from Egypt, 33.4\% of subjects reported perceiving FGM as a religious tradition which was the most important reason for continuation of the practice in that country. Seventy-two percent of ever married women reported that FGM is an important part of their religious tradition. Similarly, religion appeared to be an important factor in Burkina Faso, where education was associated with reduced likelihood of undergoing FGM for Christians but not for Muslims. ${ }^{13}$ In this study, cultural and religious reasons were not studied in depth, apart from the community perception of the practice being an inherited norm, so this needs to be investigated further. Likewise, $30 \%$ of women in Kenya supported continuation of the practice to maintain virginity., ${ }^{4,6}$

In Ethiopia, the distribution of Muslims and Christians is not uniform. For instance, Christians dominate in the north, south, and central part of the country, whereas Muslims occupy the eastern, north-eastern, and south-western parts. However, the prevalence and reasons for FGM among the religions vary and need further intensive investigation; in one area of the country, FGM might be more common among Christians whereas in another area it might be more common among Muslims, and vice versa. With regard to cultural reasons, it has been suggested that FGM can be seen as a tool for increasing social cohesion among communities, hence it is considered as a binding force in social life. ${ }^{10}$

The likelihood of girls and women undergoing FGM might be related to socioeconomic factors. In this study, more than $80 \%$ of the women were illiterate and unemployed. Therefore, the practice of FGM can be considered to be a societal norm and a source of income for the perpetuators. Girls terminate their education to meet their family responsibilities at an earlier age, and the options would be marriage or becoming engaged. In Ethiopia, there is a tendency for families with no or little education to keep their sons and daughters at home to serve the family and help with agricultural work. Therefore, poverty, lack of education, insufficient information, and inadequate knowledge might put these women at risk of becoming victims of FGM. The majority of women in Ethiopia are of low socioeconomic status and thus might be forced to accept their community's harmful traditional practices and enter into early marriage. Families might also consider marriage for girls who have undergone FGM as a means of integrating them into a new life. This study did not specifically address socioeconomic risk factors related to FGM.

Most of the women interviewed had undergone FGM during childhood, but age-specific investigation was not included in this study. The country has no birth records, and not all respondents could report their date of birth accurately, which explains the $6.2 \%$ of missing values in the questionnaire item concerning age. Other surveys have found that $90 \%$ of girls who have undergone FGM have been aged 5-14 years, and although practices vary from country to country, FGM is generally done among girls younger than 10 years. When subjected to the procedure, $50 \%$ of those cut in other regions of Ethiopia, Mali, and Mauritania were under 5 years of age, whereas $76 \%$ of those in Yemen were not more than two weeks of age. ${ }^{5}$

If the procedure is done during childhood, it leaves a scar that narrows the female genitalia and complicates childbirth, causing injury, and has a negative impact on sexuality at a later age. ${ }^{14-16}$ Since the practice is forceful and aggressive, and performed without the consent of the victim, it is unethical, 
and even more so when performed on young girls who are put through enormous suffering. The procedure and its consequences might cause physical and psychological trauma resulting in poor quality of life and self-esteem during adulthood. The procedure is particularly severe for very young girls who suffer excruciating pain due to the procedure being performed without anesthesia, and its complications.

In our study, the type of FGM most commonly practiced was clitoridectomy (type 1), with few women having undergone infibulation, which is the most severe form of FGM. ${ }^{2}$ Another study revealed that half of all victims of FGM in Ethiopia had undergone clitoridectomy. Nationwide, 6\% of females affected by FGM have undergone infibulation and more than $80 \%$ of women in the Somali region have been victims of the most severe form of FGM, along with $60 \%$ in the Afar region. ${ }^{9}$ This indicates that the practice is more common in the eastern part of the country, where the study site was located. This is reflected in the results, showing that people perceived and accepted FGM as a routine procedure. This practice very probably is culturally and religiously rooted, and has become adapted in the community over centuries. However, the prevalence of the severe form of FGM (infibulation) seemed to be low in this study as compared with regional figures for the Somali and Afar regions..$^{9,10,17}$ The study results can give no possible explanation for this difference.

Our study enquired about the health and reproductive consequences perceived in general in the community among those who knew about FGM $(\mathrm{n}=327)$ practice as well as among those who had undergone FGM $(n=792)$. Both groups knew and recognized that this practice has negative consequences for delivery, first sexual intercourse, and during menstruation. These results are consistent with findings from other countries where FGM is common; further they have shown that the risk of developing both short-term and long-term complications is more common than among those who do not undergo FGM. ${ }^{18}$ Women who have undergone any form of FGM are traumatized and likely to develop physical, psychological, and social problems associated with it. Furthermore, women with type 2 and 3 FGM are more likely to require cesarean section and have postpartum blood loss than women who had not had FGM. Studies on the psychological effects of FGM are scarce and need to be given due emphasis, given that FGM is one of the reported risk factors for post-traumatic stress disorder in women. ${ }^{15,16,18-21}$ The mechanism by which FGM might cause adverse obstetric outcomes is unclear, but they can be predicted according to the type of FGM performed; more severe complications are anticipated after type 2 than type 3 FGM. The presence of scar tissue which is less elastic than the perineal and vaginal tissue following the procedure would cause obstruction, tears, and/or a need for episiotomy. ${ }^{1,5}$

In addition to this, FGM contributes to high health care demands and medical costs. Spontaneous deliveries do not need as many health care resources as cesarean sections or other assisted deliveries. For a low resource setting like Ethiopia, where provision of any health care is a challenge, FGM puts an unnecessary burden on the country's health care system. Further, the procedure requires local specialists to handle complications at an advanced level. Due to this burden and high demand for health care, the country might lose its health care work force, with an increased number of orphans due to loss of their mothers. Since the procedure is mostly done in unhygienic conditions, it is reasonable to predict transmission of contagious and blood-borne diseases, including human immunodeficiency virus due to use of the same instruments in multiple operations. Newborns from mothers who have undergone FGM might have a complication during birth ${ }^{18}$ and birth injury that may be costly to treat afterwards. A World Health Organization study in six African countries revealed that the annual cost of FGMrelated obstetric complications amounted to $\$ 3.7$ million and ranged from $0.1 \%-1 \%$ of government spending on health care for women aged $15-45$ years. ${ }^{22}$ This poses a significant economic burden on poor countries, when forced to spend a huge amount of money on outcomes of a traditional nontherapeutic procedure.

Our study also attempted to ascertain women's feelings after observing serious outcomes of FGM which many women have faced. Some women who had seen others undergoing FGM reported feeling frightened while others approached it as a normal phenomenon, and none had attempted to stop the practice in their community. This means women might not have adequate knowledge about the potentially serious reproductive outcomes of FGM. ${ }^{23,24}$ Limited knowledge of FGM in the Kersa community shows that there is a gap in understanding of the procedure and its impact on women's reproductive health and social life. If there was good knowledge and understanding in the Kersa community, motivation towards stopping the practice would have been greater. The finding that the majority of women took no action and knew little about stopping the practice might be due to inadequate knowledge and lack of information. Therefore, information, communication, and integration are very important in the community. Western societies have recommended advocacy at school, training of 
health workers in the management of victims, recognition and training of the perpetuators, and implementation of laws alongside strategies designed to outlaw the practice. ${ }^{17,25,26}$ It is clear that in addition to the country's existing policy, adoption of such strategies in Kersa and across regions in Ethiopia would be valuable for stopping the practice. Further, success in stopping FGM should start at the grass roots level by involving all potentially concerned community members (religious leaders, advocates, educators) to work towards a generation safe from FGM.

FGM is performed for various reasons, but according to this study was mainly done to prevent women from hyperactivity in sexual practice and early initiation of sexual intercourse before marriage. In another study, similar findings were reported by $30 \%$ of Kenyan women who supported this practice to preserve female virginity. ${ }^{4}$ Similarly, more than half of Egyptian women believed that FGM would prevent adultery and that it is proof of a girl's virginity and perceived that it improves marriage prospects for unmarried girls in Nigeria. ${ }^{4,6}$ This shows that traditional and religious reasons for practicing FGM are also widely accepted by females in the societies in different regions. However, the association between religion and FGM needs further research in Ethiopia. It is quite evident that the perception and acceptance of harmful traditional practices, including FGM, is widespread across all regions, regardless of religious practices. In this study, it was identified that circumcision of daughters was associated with religion and ethnicity, and women who did not own a radio were more likely to have their daughters circumcised. This emphasizes the importance of further research on cultural and social factors, and working on communication of information and education by involving the media as an agent.

In this study, three quarters of FGM procedures were performed by local healers, mostly using unhygienic procedures in the community, thus increasing the risk of infection and later reproductive complications in women undergoing FGM. In some countries, medical personnel, including doctors, nurses, and certified midwives perform FGM under anesthesia in health care facilities, even though it is forbidden and subject to prosecution in the west. The highest rate of use of medical personnel to perform FGM can be found in Egypt (61\%), Kenya (34\%), and Sudan (36\%), with rates of $9 \%$ and $13 \%$, respectively, in Guinea and Nigeria. Similarly, 90\% of FGM is performed in Guinea and Eritrea by traditional/ local healers. ${ }^{3}$ From this, it can be assumed that in some countries the practice is totally dominated by local healers using unhygienic practices which might put girls and women at risk of contracting other contagious diseases, including human immunodeficiency virus and acquired autoimmune deficiency syndrome. Local healers might be trained as traditional birth attendants or be untrained practitioners, but regardless, FGM harms the health of its victims. It is a source of income for some practitioners in Ethiopia and they are well known in society, although they have started to perform FGM in hidden areas because of the new legislation and risk of prosecution. Many countries have introduced legislation alongside their strategies to combat FGM, which in some countries results in imprisonment whether it is performed inside or outside the country where the daughters live. ${ }^{27-29}$ In 2004, the Ethiopian government modified its legislation by making FGM a criminal act. However, Ethiopia has had problems in implementing the law because no complaints were reported or filed until the end of $2008 .{ }^{30}$ This indicates a low level of community involvement and awareness, suggesting that information about the new law has not been properly disseminated in the community.

In Ethiopia, 85\% of the country's population is engaged in farming and resident in the countryside, and according to local tradition, women are likely to be servants to their husbands and to help in farming. This may prevent women from having an education and accessing reproductive health care information. The burden of household work is solely the responsibility of young girls and women. Therefore, they may be kept at home to serve the rest of the family and take care of young children. If women are not educated, it is likely that they will continue to be victims of FGM and other harmful traditional practices in society as a norm in Ethiopia. The majority of the women interviewed reported that they did not know what FGM was all about or why they had been subjected to the practice. This can be interpreted as meaning that the women did not know the meaning of the terms "circumcision" and "genital cutting", although they clearly regarded any form of genital cutting as routine in their society. This knowledge gap may be due to lack of dissemination of health information as well as community integration towards combating FGM. In Ethiopia, social life, religion and culture are more tightly integrated than in other countries.

Social systems are key to families not being isolated. Therefore, some families are forced to practice FGM due to fear of discrimination for deviating from community norms. This integrated practice forces some immigrant Ethiopians in the western world to continue their traditional norms, including FGM. There is a lack of research among Ethiopian diaspora and their traditional practices in the west. Much work needs to be done because FGM is also illegal in 
the west and taxes the health care systems of host countries as a result of obstetric complications. Further, the practice violates women's legal rights in host countries that have started implementing World Health Organization strategies and partnering organizations' recommendations against FGM. According to the principles of medical ethics, FGM is maleficence, but the practice has not been the subject of detailed research in Ethiopia. It may be a great challenge to change community perception of FGM in Ethiopia because grass roots action is necessary to create awareness and convince people who have inherited FGM as a legacy from their ancestors, traditions, and religious leaders to abandon the practice.

The Ministry of Health in Ethiopia has designed a strategy to stop FGM in consultation with traditional community associations and local healers. This has been done because it was realized that without them all actions were doomed to failure, and imposing the new legislation alone would be unsuccessful. Local healers who intended to continue FGM were being contacted to stop the practice and a new self-help project was designed to support them financially, because some performers practice FGM to earn money and were advocating that FGM should be continued. The new policy to end FGM in Ethiopia includes implementation of the law at the level of families and those who perform it by any means. This policy is effective and currently being implemented in addition to considering traditional, ethical, and religious issues to harmonize implementation. However, FGM is still a public health problem to address across the entire country. ${ }^{30,31}$

The practice of FGM is a violation of human rights and has to be stopped altogether. Integrated efforts by policymakers, the Ministry of Health, and international organizations are needed all over the country. It might continue to be a challenge in public health practice, but educating women is likely to have the most impact. The younger generation is growing up with reproductive rights as well as protection from violence enforced by tradition. To achieve these goals, it is recommended to handle religious leaders and perpetuators in a respectful way, while condemning the practice and providing health information. This is very important and could be a key factor in policy-making.

\section{Conclusion}

Female genital cutting/mutilation is a common practice in the eastern part of Ethiopia. However, only one third of the respondents reported knowing of FGM being practiced in their community. It is clear that there was a knowledge gap in the community where the prevalence was actually high. Mothers had circumcised one or more of their daughters and the majority of mothers were circumcised themselves. Daughter circumcision showed an association with religion and ethnicity. The main perpetuators of FGM in Kersa were found to be local healers, an issue which needs serious attention when designing a policy to combat the practice.

Some of the women knew the negative reproductive health consequences of FGM and had experienced them during sexual intercourse and childbirth. However, with regard to stopping FGM, few of them had tried to do so and the majority had not taken any steps towards stopping the practice. This may be attributable to the cultural system and fear of isolation. The principal reason for performing FGM is to reduce hypersexuality before marriage. This perception has no scientific justification and hampers women's self-determination in the area of sexuality. Therefore, FGM violates the right of girls and women to determine their own reproductive health and sexuality. Furthermore, it has healthrelated consequences and complications, and increases health care demands in Ethiopia, already a resource-poor country.

\section{Acknowledgments}

We would like to acknowledge Haramaya University, which established demographic surveillance and a health research center in Kersa, the people of Kersa woreda/locality, the authorities in the region, and data collectors for their cooperation.

\section{Disclosure}

The authors report no conflicts of interest in this work.

\section{References}

1. World Health Organization. Eliminating female genital mutilation an interagency statement: UNAIDS, UNDP, UNECA, UNESCO, UNFPA, UNHCHR, UNHCR, UNICEF, UNIFEM. Geneva, Switzerland: World Health Organization; 2008

2. Center for Reproductive Rights. Female genital multilation. A Matter of human rights. An advocate's guide to action. 2nd ed. New York: Center for reproductive rights; 2006. Available from: http://reproductiverights org/sites/default/files/documents/FGM_final.pdf. Accessed February 8 , 2012.

3. Banda F. National legislation against female genital mutilation. Eshborn, Germany: German Technical Cooperation; 2003.

4. PATH. Female genital mutilation in Africa. An analysis of current abandonment approaches. Nairobi: PATH; 2005. Available from: http:// www.path.org/publications/files/CP_fgm_combnd_rpt.pdf. Accessed February 8, 2012.

5. WHO. Progress in sexual and reproductive health research. Geneva: WHO; 2006.

6. Tag-Eldin MA, Gadallah MA, Al-Tayeb MN, Abdel-Aty M, Mansour E, Sallem M. Prevalence of female genital cutting among Egyptian girls. Bull World Health Organ. 2008;86:269-274. 
7. Getachew I. Fighting female genital mutulation/cutting in Ethiopia's Somali region. Addis Ababa: UNICEF; 2006. Available from: http://www.unicef. org/ethiopia/ET_real_2006_FGM.pdf. Accessed on February 8, 2012.

8. United States Department of State, Ethiopia: Report of female genital mutilation (FGM) or female genital cutting (FGC), June 1, 2001. Available at: http://www.unhcr.org/refworld/docid/46d57877c.html. Accessed May 2, 2011.

9. Deutsche Gesellschaft für Technische Zusammenarbeit GmbH. Female genital mutilation in Ethiopia. Eschborn: GTZ; 2007. Available from: http://www.gtz.de/de/dokumente/en-fgm-countries-ethiopia.pdf. Accessed February 8, 2012.

10. Amare D, Aster B. Baseline survey on female genital mutilation and other harmful traditional practices, in North Gondar, Amhara Regional State. Feb 2006. Available at: http://www.africanchildinfo.net/docu ments/BS\%20PDF6.pdf. Accessed May 3, 2011.

11. Genet M, Wakgari D. Prevalence and associated factors of female genital mutilation among Somali refugees in eastern Ethiopia. BMC Public Health. 2009;9:264.

12. Central Statistical Agency. Ethiopia demographic and health survey 2005. Addis Ababa: CSA; 2005. Available from: http://www.etharc.org/ amhara/Asset/Dowloadables/DHS\%202005\%20Ethiopia.pdf. Accessed February 8, 2012.

13. Karmaker B, Kandala NB, Chung D, Clarke A. Factors associated with female genital mutilation in Burkina Faso and its policy implications. Int J Equity Health. 2011;10:20.

14. World Health Organization. Female genital mutilation, integrating prevention and the management of health complications into the curricula of nursing and midwifery. Teacher's guide. Geneva: WHO; 2001.

15. Female genital mutilation fact sheets, Forward 2005. Available at: http:// www.forwarduk.org.uk/download/11. Accessed January 13, 2012.

16. Jasmine A, Christine M, Michel B, Oliver I. Care of women with female genital mutilation/cutting. Available at: http:/www.smw.ch/content/ smw-2011-13137/. Accessed April 15, 2011.

17. Ministry of Health New Zealand: Female genital mutilation teaching module. FGM education program for the New Zealand Ministry of Health, November 2009. Available at: http://www.fgm.co.nz. Accessed July 7, 2011.

18. Banks E, Meirik O, Farley T, Akande O, Bathija H, Ali M. Female genital mutilation and obstetric outcome: WHO collaborative prospective study in six African countries. Lancet. 2006;367:1835-1841.

19. The consequences of female genital mutilation, from African women organization. Available at: http://www.african-women.org/FGM/consequences.php. Accessed June 25, 2011.
20. IRIN. Razor's edge. The controversy of female genital mutilation. Nairobi: IRIN; 2005. Available from: http://www.irinnews.org/pdf/ in-depth/FGM-IRIN-In-Depth.pdf. Accessed February 8, 2012.

21. Behrendt A, Moritz S. Posttraumatic stress disorder and memory problems after female genital mutilation. Am J Psychiatry. 2005;162: 1000-1002.

22. Bishai D, Bonnefant Y-T, Darwish M, et al. Estimating the obstetric costs of female genital mutilation in six African countries. Available at: http:/www.who.int/bulletin/volumes/88/4/09-064808/en/index.html. Accessed January 11, 2012.

23. Dorkenoo E, Morison L, Macfarlane A. A statistical study to estimate the prevalence of female genital mutilation in England and Wales. Summary report. London: FORWARD; 2007. Available at: http://www. forwarduk.org.uk/download/96. Accessed February 8, 2012.

24. Althaus FA. International family planning perspective: Special report on female genital mutilation; rite of passage or violation of rights? Int Fam Plan Perspect. 2007;23:130-133.

25. Ending FGM. Strategy for European institutions: Available at: http:// http://www.endfgm.eu/content/assets/END_FGM_Final_Strategy.pdf. Accessed April 7, 2011.

26. Johnsdotter S. Swedish legislation regarding "female genital mutilation" and implementation of the law, evaluating the impact of existing legislation in Europe with regard to female genital mutilation. Ghent University International Center for Reproductive Health, Dec 2003

27. Turillazzi E, Fineschi V. Female genital mutilation: The ethical impact of the new Italian law. J Med Ethics. 2007;33:98-101.

28. Sara J. The FGM legislation implemented: experiences from Sweden, Malmö University January 2009. Available at: http://www.uv.es/CEFD/ Index_17.htm. Accessed July 1, 2011.

29. United Nations. Good practices in legislation on "harmful practices" against women. New York: UN; 2009. Available from: http://www. un.org/womenwatch/daw/egm/vaw_legislation_2009/Final\%20 report\%20EGMGPLVAW.pdf. Accessed February 8, 2012.

30. Deutsche Gesellschaft für Technische Zusammenarbeit GmbH. Good practice: harmonising traditional norms and national law in Ethiopia. Eschborn: GTZ; 2008. Available from: http://www.intact-network.net/ intact/cp/files/1284971634_23-\%20Harmonising\%20traditional\%20 norms $\% 20$ and $\% 20$ national\%20law\%20-\%20Ethiopia\%20(GTZ\%20 08).pdf. Accessed February 8, 2012.

31. Global strategy to stop health care providers from performing female genital mutilation. Available at: whqlibdoc.who.int/hq/2010/WHO_ RHR_10.9_eng.pdf. Accessed January 11, 2012.
International Journal of Women's Health

\section{Publish your work in this journal}

The International Journal of Women's Health is an international, peerreviewed open-access journal publishing original research, reports, reviews and commentaries on all aspects of women's healthcare including gynecology, obstetrics, and breast cancer. Subject areas include: Chronic conditions (migraine headaches, arthritis, osteoporosis);

\section{Dovepress}

Endocrine and autoimmune syndromes; Sexual and reproductive health; Psychological and psychosocial conditions. The manuscript management system is completely online and includes a very quick and fair peer-review system. Visit http://www.dovepress.com/ testimonials.php to read real quotes from published authors. 